\title{
Direct Observation of Hydrogenation and Dehydrogenation of a
}

\section{Zirconium Alloy}

\author{
H. H. Shen ${ }^{1,2}$, X. T. Zu ${ }^{1 *}$, B. Chen ${ }^{3}$, C. Q. Huang ${ }^{3}$, K. Sun ${ }^{2 *}$ \\ ${ }^{1}$ School of Physical Electronics, University of Electronic Science and Technology of China, \\ Chengdu 610054, Sichuan, China \\ ${ }^{2}$ Department of Materials Science and Engineering, University of Michigan, Ann Arbor, \\ Michigan 48109, USA \\ ${ }^{3}$ Institute of Nuclear Physics and Chemistry, China Academy of Engineering Physics, \\ Mianyang 621900, Sichuan, China
}

${ }^{*}$ Correspondence should be addressed to:

No. 4, Section 2, North Jianshe Rd. Chenghua District, Chengdu City, Sichuan Province, 610054, China. Tel: +8628 83202130, Email: xtzu@uestc.edu.cn (X.T.Zu)

Building 22, Room G013, North Campus Research Complex, 2800 Plymouth Road, Ann Arbor, MI 48109-2800 USA. Tel: +1 734936 3353, Email: kaisun@umich.edu (K. Sun) 


\section{Abstract}

The hydrogenation and dehydrogenation behaviors of a zirconium alloy were in-situ studied by scanning electron microscopy and transmission electron microscopy. The zirconium alloy can absorb hydrogen to form $\mathrm{Zr}$ hydride which is enhanced by the relaxation of inner stress in the alloy. The hydrogen is generated from an ion/electron beam stimulated decomposition of an organometallic precursor, trimethyl (methylcyclopentadienyl) platinum (IV), in a scanning electron microscope and focused ion beam system. The formed $\delta$-type zirconium hydride that has a face centered cubic structure was observed to grow as preferentially oriented platelets in the zirconium alloy matrix. The platelets have a common crystallographic relationship of $[010]_{\alpha} / /[1-10]_{\delta_{2}}(001)_{\alpha} / /(111)_{\delta}$. The dehydrogenation of the zirconium hydride was in-situ investigated in a transmission electron microscope by heating the materials. It was found that the $\delta-\mathrm{ZrH}_{1.5-1.66}$ hydride transformed into $\zeta-\mathrm{ZrH}_{0.25}$ at $450{ }^{\circ} \mathrm{C}$ even at a longer heating time. The experiment demonstrates a new way for in-situ study of hydrogenation behaviors of other hydrogen storage alloys.

Keywords: Zirconium alloy; Hydride platelet; Dehydrogenation; Stress relaxation; In-situ observation. 


\section{Introduction}

Metal hydrides are one option under consideration for hydrogen storage in solid state for alternative energy applications. Zirconium [1-3] and its alloys [4-6] are important $\mathrm{H}$ storage materials owing to their high storage capacity of $\mathrm{H}$ [3] and strong stability of $\mathrm{Zr}$ hydrides $[7,8]$. The main requirements of a $\mathrm{H}$ storage material are very low absorption pressure at room temperature and a high $\mathrm{H}$ storage capacity. Shi et al. [3] reported their ability to attain the theoretical maximum $\mathrm{H}$ storage capacity $(\mathrm{H} / \mathrm{Zr}=2)$ when exposing $\mathrm{Zr}$ films to $\mathrm{H}$ with relative low contamination and a hydrogen pressure of $\sim 2 \mathrm{~Pa}$ and a substrate temperature of $120{ }^{\circ} \mathrm{C}$ for $10 \mathrm{~min}$. Tritium-zirconium targets have also been prepared by absorbing gaseous tritium in thin $\mathrm{Zr}$ metal foils. It was found that maximal absorption of tritium could be obtained by holding the $\mathrm{Zr}$ thin foil at about $600{ }^{\circ} \mathrm{C}$ for a few minutes, followed by cooling to room temperature [1].

In addition, the $\mathrm{Zr}-\mathrm{H}$ reaction is concerned for the fuel cycles in fusion reaction $[8,9]$. $\mathrm{Zr}$ and its alloys have also been used as the fuel cladding and structural materials in nuclear reactors due to their low thermal neutron absorption cross sections, good mechanical performance and corrosion resistance.

In nuclear reactors, the performance of $\mathrm{Zr}$ fuel cladding is susceptible to degradation partly due to $\mathrm{H}$ pickup that induces the precipitation of brittle $\mathrm{Zr}$ hydride [10]. If a loss-of-coolant accident occurs in a reactor, free $\mathrm{H}_{2}$ gas would be produced by the reaction between the hot $\mathrm{Zr}$ alloy cladding material on the surface of fuel rods and the water vapor. Part of the $\mathrm{H}$ would be absorbed by the metallic $\mathrm{Zr}$ alloy [11] resulting in the hydrogenation of the $\mathrm{Zr}$ alloy, as the solubility of $\mathrm{H}$ in $\mathrm{Zr}$ is below $10 \mathrm{wt}$. ppm at room temperature [12]. Three types of Zr hydrides have been reported and presented in the Zr-H phase diagram [11], the $\gamma$-, and $\varepsilon$-type face centered tetragonal (fct) phases $[13,14]$, and the $\delta$-type face centered

cubic (fcc) phase [15]. The $\delta$-type hydride is stable at room temperature (RT) and is 
considered to be a potential for hydrogen storage in solid phase. Recently, Zhao et al. [16]

reported a new $\mathrm{Zr}$ hydride namely $\zeta$-type hydride formed at RT in a cathodic hydrogen charged Zircaloy-4 sample. The $\zeta$-type hydride belongs to the trigonal system with space group $\mathrm{P} 3 \mathrm{~m} 1$ and it is fully coherent with the $\mathrm{Zr}$ matrix [16]. The hydrogenation of the $\mathrm{Zr}$ alloys was reported to experience a phase transformation with a volume expansion of $12.3 \%$ for $\alpha \rightarrow \gamma$ and $17.2 \%$ for $\alpha \rightarrow \delta$ [13]. The hydrogenation or deuteration of $\mathrm{Zr}$ alloys in the reactors resulting in problems such as embrittlement and strength degradation of the alloys [9]. Therefore, there has been great interest in the study of the hydrogenation behaviors of the alloys.

Even though many experiments have been performed on the study of the H pickup and $\mathrm{H}$ diffusion behaviors in a Zr matrix, there are only a few in-situ experiments reported in the literature [10-12]. The $\mathrm{H}$ diffusion in Zircaloy-4 was investigated by means of in-situ neutron radiography experiments [11]. The activation energy of $\mathrm{H}$ diffusion in Zircaloy-4 was determined as $55.4 \mathrm{~kJ} / \mathrm{mol}$. Colas et al. [12] reported that the $\mathrm{Zr}$ hydrides would be re-orientated under an external stress load as observed by an in-situ synchrotron radiation method. It was suggested that a threshold stress for hydride re-orientation is between 75 and $80 \mathrm{MPa}$ for Zircaloy. A stress induced transformation from $\delta$-type hydride to $\gamma$-type hydride via ordering of the $\mathrm{H}$ atoms was suggested by Steuwer et al. [10] who performed an in-situ uniaxial mechanical tensioning experiment on hydride-containing Zircaloy-2 and Zircaloy-4 specimens using energy-dispersive synchrotron X-ray diffraction. Kuroda et al. [17] described that the hydrogenation could be the dominant factor affecting the strength degradation of Zircaloy claddings. The induced degradation depends on the distribution and orientation states of the hydride precipitates. Transmission electron microscope (TEM) coupled with an ion accelerator was utilized by Shinohara et al. [18] to perform an in-situ investigation on the growth process of Zr hydrides in Zircaloy-4. In their study, the growth 
processes of $\mathrm{Zr}$ hydrides accompanying the formation of dislocations were observed in the intergranular and intragranular grain of the Zircaloy during the hydrogen ion implantation [18]. Although those reported experiments have given us information on hydrogenation of different $\mathrm{Zr}$ alloys, the direct observation of $\mathrm{Zr}$ hydride precipitation during hydrogenation still remains unknown.

A lot of work has been done on the desorption behavior of $\mathrm{Zr}$ hydrides [7, 13, 19-21] by experimental techniques of thermal desorption spectroscopy (TDS) [20], differential scanning calorimeter (DSC) [22], in-situ X-ray diffraction [13, 23], thermogravimetric analysis (TGA) [24], and also by theoretical method based on the density functional theory (DFT) [25]. Nevertheless, the stability of various hydride phases is still debated, as such studies are working on bulk samples on the macroscopic scale. The stability of the hydrides is strongly correlated to the multiple kinds of material properties and defect status of the $\mathrm{Zr}$ matrix [10, 22-27]. Recent studies indicate that the stability and occurrence of the $\mathrm{Zr}$ hydrides is a complex phenomenon, where the stress in the matrix $[10,26]$, matrix yield strength [23], alloying additions [25], $\beta$-Zr distribution [23, 27] and ion irradiation [22] all have pronounced effects on the desorption kinetics of $\mathrm{Zr}$ hydrides. It has been demonstrated that nanoscale systems exhibit significant thermodynamic deviation from the bulk [28]. Therefore, it is necessary to estimate the desorption kinetics of the $\mathrm{Zr}$ hydride without the influence of the crystalline Zr matrix.

In the present study, we introduce a new methodology, based on a focused ion beam (FIB) system, for an in-situ study of hydrogenation behavior of a $\mathrm{Zr}$ alloy during the $\mathrm{H}$ uptake process. The TEM sample preparation called flash polishing was employed to obtain the individual platelet for better characterizing the desorption kinetics of Zr hydride. The desorption kinetics of $\mathrm{Zr}$ hydride are investigated by the combination of electron energy-loss spectrometer (EELS) and selected area electron diffraction (SAED) in TEM. 


\section{Experimental methods}

\subsection{Material preparation}

The as-received $\mathrm{Zr}$ alloy, consisting of $\mathrm{Zr}, \mathrm{Sn}, \mathrm{Nb}, \mathrm{Fe}, \mathrm{Cr}$ elements, was provided by Nuclear Power Institute of China [29, 30]. The Zr-Sn-Nb-Fe-Cr plate was prepared by the following procedures: (a) forge an ingot with composition of $1.0 \mathrm{wt} . \% \mathrm{Sn}, 0.3 \mathrm{wt} . \% \mathrm{Nb}, 0.3$ wt. $\% \mathrm{Fe}, 0.1 \mathrm{wt} . \% \mathrm{Cr}$ and 98.3 wt. $\% \mathrm{Zr}$, in the temperature range of $900-1100{ }^{\circ} \mathrm{C}$; (b) quench the melting billet at $1000-1050{ }^{\circ} \mathrm{C}$; (c) cold roll the billet into plate at $600-700{ }^{\circ} \mathrm{C}$; (d) finally anneal the plate at $560-600{ }^{\circ} \mathrm{C}$. The final chemical composition of alloy measured by energy dispersive spectroscopy (EDS) in a TEM is 1.6 wt. $\% \mathrm{Sn}, 0.6$ wt. $\% \mathrm{Nb}, 0.2$ wt.\%Fe, 0.1 wt. $\% \mathrm{Cr}$, and 97.5 wt. $\% \mathrm{Zr}$,

\subsection{In-situ observation of $\mathrm{Zr}$ alloy hydrogenation}

The hydrogenation of the $\mathrm{Zr}$ alloy was observed in a FIB system through a lamella thinning process. A thin lamella with a thickness around $1 \mu \mathrm{m}$ was cut from the bulk Zr alloy by the lift-out method [31]. Then, the lamella was glued onto a half TEM grid at its two ends by platinum deposition to reduce the lamella deformation caused by the stress relaxation. In order to observe the $\mathrm{Zr}$ alloy hydrogenation process, a designed thinning procedure with two steps was applied to the lamella. A series of SEM images taken while the lamella was undergoing the $\mathrm{Ga}$ ion beam thinning are displayed in Figure 1. Firstly, the ion beam thinning was performed on the right half of the thin lamella denoted by the rectangle frame. As shown in Figure 1(a) to Fig. 1(c), the thickness of thin lamella decreases with the increase of ion thinning time. The SEM image of original lamella before it was further thinned down is shown in Figure 1(a). Many platelet features appear in the thinning area (Fig. 1(b)), and the platelet features become much clearer in Fig. 1(c). Those platelets seem to be 
preferentially precipitated in the Zr matrix. Secondly, $\underline{\text { ion beam }}$ thinning was performed on the left half of the thin lamella. With continuous ion milling, the platelet features change from unnoticeable in the Fig. 1(d) to remarkable in Fig. 1(e)-(f) when it was further thinned down to about $100 \mathrm{~nm}$.

Bright-field (BF) images taken from the $\mathrm{Zr}$ alloy are shown in Fig. 2, the thin lamella with a thickness around $200 \mathrm{~nm}$ is compared to that taken from exactly the same area after it had been further thinned down to $100 \mathrm{~nm}$ by the ion beam (Fig. 2(a) and (b), respectively). Before final thinning was applied, only dislocation lines were observed in the alloy (indicated by arrows in Fig. 2(a)). After final thinning, a large number of platelets denoted by arrows were observed to form in the $\mathrm{Zr}$ alloy with preferential orientations. The lengths of the platelets are nonuniform and ranging from $\sim 100 \mathrm{~nm}$ to $\sim 500 \mathrm{~nm}$ which are in agreement with those observed during hydrogenation in SEM.

\subsection{Thin lamella preparation for in-situ dehydrogenation investigation in TEM}

Thin lamella for in-situ dehydrogenation investigation through heating in a TEM was prepared using the procedure mentioned above followed by a flash electrochemical polishing procedure that was initially developed to remove the surface radiation damage layer introduced by Ga FIB [32]. In the present study, the flash polishing was designed to dissolve/thin the $\mathrm{Zr}$ matrix leaving the $\mathrm{Zr}$ hydride platelets in the dissolved $\mathrm{Zr}$ matrix. The etchant is 4 vol.\% perchloric acid mixed with 96 vol.\% methanol. The flash polishing was performed at $-40{ }^{\circ} \mathrm{C}$ and operated at an applied voltage of $12 \mathrm{~V}$ for $0.03 \mathrm{~s}$.

\subsection{Electron microscopy characterizations}

A FEI Helios 650 Nanolab workstation was used for the study of in-situ hydrogenation and the microstructure changes of the alloy during the $\mathrm{H}$ uptake process. To further study the 
microstructure and analyze the phases of the hydrogenated alloy, a JEOL JEM 2010F TEM running at $200 \mathrm{kV}$ was used. Selected area electron diffraction (SAED), high resolution TEM (HRTEM) and BF imaging were performed in TEM mode. Scanning transmission electron microscopy (STEM) BF and annular dark field (ADF) images were also acquired from the specimens using a JEOL JEM $2100 \mathrm{~F}$ with a CEOS hexpole probe corrector working at $200 \mathrm{kV}$ in STEM mode.

EELS tests were carried out on a JEOL JEM3100R5 TEM operated at $300 \mathrm{kV}$. The microscope was equipped with a cold-field emission gun, double Cs-Correctors and a Gatan 965 Quantum imaging filter. All the EELS collections were performed in STEM mode using a $30 \mu \mathrm{m}$ condenser aperture, a $20 \mathrm{~mm}$ camera length, a $5 \mathrm{~mm}$ spectrometer entrance aperture and at a dispersion of $0.05 \mathrm{eV}$ per channel. This configuration corresponds to a convergence semi-angle of $22 \mathrm{mrad}$, a Gatan DF detection semi-angle of $41.5 \mathrm{mrad}$ and energy resolution of $1 \mathrm{eV}$. Dual-EELS spectra with both low-loss region (-5 - $95 \mathrm{eV})$ and high-loss region (500 - $600 \mathrm{eV}$ ) were recorded at the same time. The exposure time of $0.5 \mathrm{~s}$ and $3 \mathrm{~s}$ was used to record the low-loss region and high-loss region spectra, respectively. EELS line scan and mapping were acquired with a dwell time of $0.5 \mathrm{~s}$ at a step size of $0.5 \mathrm{~nm}$ and pixel size of 2 $\mathrm{nm} \times 2 \mathrm{~nm}$, respectively.

The TEM lamella with denuded orientated platelets were mounted onto a Gatan 652 double-tilt heating holder for in-situ dehydrogenation study up to $700{ }^{\circ} \mathrm{C}$ at an interval of 50 ${ }^{\circ} \mathrm{C}$ with a temperature ramping rate $20{ }^{\circ} \mathrm{C} / \mathrm{min}$.

\section{Results and discussions}

\subsection{Identification of phase and composition of the platelet}

HRTEM images and SAED patterns taken from the $\alpha$-Zr alloy matrix and a platelet are shown in Figure 3. The intergrowth of the $\alpha$-Zr alloy matrix and a hydride platelet is shown 
in Figure 3(a). The SAED pattern in Fig. 3(b) is a composite one consisting of the [010] from the $\alpha-\mathrm{Zr}$ alloy matrix and the [1-10] zone axis of the $\delta$-type $\mathrm{Zr}$ hydride consistent with commonly acceptable statements that the $\delta$-type Zr hydride is the most predominant phase at room temperature [15]. The enlarged HRTEM images from the $\mathrm{Zr}$ alloy matrix and the $\delta$-type Zr hydride are separately shown in Fig. 3(c) and 3(d). The above analysis confirms that those two phases have an epitaxial relationship of $[010]_{\alpha-\mathrm{Zr}} / /[1-10]_{\delta-\mathrm{ZrH}}$, $(001)_{\alpha-\mathrm{Zr}} / /(111)_{\delta-\mathrm{ZrH}}$, which is in good agreement with the previous studies $[12,18,33-35]$.

STEM-BF image of a Zr hydride platelet embedded in the Zr matrix is shown in Figure 4(a). EELS spectra collected from both of platelet and Zr matrix were shown in Fig. 4(b). Two EELS spectra were collected from the points labeled as A and B in Fig. 4(a), which correspond to the areas of $\mathrm{Zr}$ matrix and hydride platelet. Those two spectra were normalized to the energy loss peak height at $42 \mathrm{eV}$. The peaks labeled as 1 and 2 in the two spectra collected from the positions $\mathrm{A}$ and $\mathrm{B}$, have energies of $16.9 \mathrm{eV}$ and $19.2 \mathrm{eV}$, respectively, which are in excellent agreement with the reported plasmon peak energies for the $\alpha$-Zr and the $\delta$-type hydride $[16,36]$. An EELS line scan along the line labeled in Fig. 4(a) was also performed and the EELS spectra collected are shown in Fig. 4(c). Two points marked by arrows in the line profile indicate the region that has not been hydrogenated. The EELS line scan indicates that the hydride was not fully hydrogenated due to the appearance of the $\alpha$-Zr inside the hydride platelet. The EELS map collected from the rectangle area denoted in Fig. 4(a) are shown in Fig. 4(d) and colored by red and green corresponding to the energy loss peaks of $16.9 \mathrm{eV}$ and $19.2 \mathrm{eV}$ in the EELS spectra of $\mathrm{Zr}$ matrix and $\delta$-hydride.

\subsection{Mechanism of $\mathrm{Zr}$ hydride formation enhanced by stress relaxation}

As having been mentioned above, two basic requirements for the $\mathrm{Zr}$ hydrogenation are needed, the generation of local stresses and the introduction of $\mathrm{H}$. According to Colas et al. 
[12] and Steuwer et al. [10], the hydrogenation behavior of $\mathrm{Zr}$ and its alloys would be strongly correlated to the local stresses [34]. In the present study, two kinds of milling procedures have been employed to do the final ion milling on the thin lamella. For the first case, the whole thin lamella was ion milled to a final thickness around $100 \mathrm{~nm}$, which is called the conventional ion milling. After ion beam thinning, the side-view and top-view images of the thin lamella are shown in Fig. 5(a) and 5(b), respectively. Obvious deformation can be observed from the top-view image, and the formation of many platelets can be observed from the side view image. The other kind of final ion beam thinning procedure called gradient ion milling was adopted, as shown in Fig. 5(c)-(d). In this case, the denoted areas ' $A$ ' to ' $D$ ' in Fig. $5(\mathrm{c})$ continuously decrease in gradient from a original thickness of $1 \mu \mathrm{m}$; Each labeled area has a typical width of $2 \mu \mathrm{m}$. Only the area ' $D$ ' was thinned down to around $100 \mathrm{~nm}$. After the ion beam thinning, no clear deformation and no platelets were observed in the lamella. It can be concluded that the stress relaxation accompanied by the lamella deformation generated during the conventional FIB milling processing provides the driving force for the Zr hydrogenation. Carr et al. [37] reported that the longitudinal macroscopic stress still exists in the Zircaloy-4 alloy after it had been heat treated at $475{ }^{\circ} \mathrm{C}$ for 30 min with only $40 \%$ reduction from that before heat treatment. A partial reduction of residual stresses after heat treatment at $530{ }^{\circ} \mathrm{C}$ for 1 hour was also found in $\mathrm{Zr}-2.5 \mathrm{Nb}$ alloy by Root et al. [38]. Therefore, it is believed that the $\mathrm{Zr}$ alloy studied here still contains some internal residual stresses even after it has been finally annealed at $600{ }^{\circ} \mathrm{C}$.

In general, platinum deposition is employed as an irradiation protective coating or to glue a thin lamella to a manipulation tip or a grid during TEM sample preparation [31]. The platinum deposition can be conducted via either an electron beam or ion beam induced deposition methods. In any case, the organometallic gas precursor was firstly flowed and adsorbed onto the sample surface. Then, the decomposition of precursor would be 
stimulated by either electron or ion beam, resulting in localized deposition of various materials [39]. Typical gas precursor used for the deposition of platinum is trimethyl (methylcyclopentadienyl) platinum (IV) $[39,40]$, which was also used in the Helios 650 FIB system. Wnuk et al. [40] demonstrated that electron irradiation stimulated desorption of

organometallic precursor. Desorption of precursor was accompanied by the evaporation of methane and $\mathrm{H}$ molecules from the adsorbate layer and the loss of $\mathrm{C}-\mathrm{H}$ groups. The electron stimulated reactions of adsorbed gas precursor can be expressed as [40]:

$$
\mathrm{MeCpPt}^{\mathrm{IV}} \mathrm{Me}_{3} \text { (Precursor) }+\mathrm{e}^{-} \rightarrow \mathrm{PtC}_{8} \text { (Adsorbed } \mathrm{PtC}_{x} \text { film) }+\mathrm{H}_{2} \text { (gas) } \uparrow+\mathrm{CH}_{4} \text { (gas) } \uparrow
$$

Hydrogen has been detected by the mass spectrometer as gas phase product during the electron/ion beam irradiation [39]. In the present study, the $\mathrm{H}$ source for the $\mathrm{Zr}$ hydrogenation is generated by electron/ion beam irradiation of the organometallic precursor. The free hydrogen gases can be consecutively produced immediately after the electron or ion beam focused on the area which is covered by the adsorbed organometallic precursor.

\subsection{In-situ investigation of dehydrogenation of the $\mathrm{Zr}$ hydride}

BF images with corresponding SAED patterns (shown in Fig. 6 (d)-(f)) taken from the hydride platelet at the temperatures of RT, $450{ }^{\circ} \mathrm{C}$ and $700{ }^{\circ} \mathrm{C}$ are shown in Figure 6(a)-(c). The hydride platelet remains a needle-like morphology without significant transformation during the heating up to $700{ }^{\circ} \mathrm{C}$. Before heating, the hydride platelet has a fcc structure corresponding to $\delta$-type $\mathrm{ZrH}_{1.5-1.66}$ phase, which is confirmed by the indexed pattern in Fig. 6(d) having a zone axis of [110]. A subtle difference was observed between the SAED patterns taken at RT and $450{ }^{\circ} \mathrm{C}$. The angle between crystal planes of $(1 \overline{1} 1)$ and $(1 \overline{1} \overline{1})$ is measured as $70.5^{\circ}$ at RT and changes to $66.9^{\circ}$ at $450{ }^{\circ} \mathrm{C}$, indicating that a phase 
transformation has occurred.

The decomposition of $\mathrm{Zr}$ hydrides with the increase of temperature has been reported in the $\mathrm{Zr}-\mathrm{H}$ system $[7,13,19-21]$. The known phases of $\zeta-, \gamma-, \delta$-, $\varepsilon$-type hydrides and pure $\alpha$-, $\beta$ - $\mathrm{Zr}$ are considered as candidate phases when indexing the new formed phase at $450{ }^{\circ} \mathrm{C}$. After carefully comparing the SAED pattern in Fig. 6(e) with the SAED patterns simulated with the crystal structure parameters of $\alpha-\mathrm{Zr}$ and $\zeta-\mathrm{ZrH}_{0.25-0.5}$, it is reasonable to index the SAED pattern in Fig. $6(\mathrm{e})$ as $\zeta-\mathrm{ZrH}_{0.25-0.5}$ structure with a zone axis of [12 $\left.\overline{1}\right]$. The SAED pattern in Fig. 6(f) is the same as that in Fig. 6(e), indicating that the $\zeta-\mathrm{ZrH}_{0.25-0.5}$ is thermally stable up to $700{ }^{\circ} \mathrm{C}$. To further verify the phase structure of hydride at $700{ }^{\circ} \mathrm{C}$, three SAED patterns were taken along different viewing directions by tilting the specimen and shown in Fig. 7(a)-(c). They are in excellent agreement with the zone axis of [ $\left.\begin{array}{lll}1 & 2 & -1\end{array}\right],\left[\begin{array}{lll}-1 & 3 & -1\end{array}\right]$ and [3 $5-1]$ of $\zeta$-hydride, respectively. In addition, polycrystalline rings observed in the SAED patterns should be arising from the nano-size $\mathrm{ZrO}_{x}$ phases in the dissolved matrix and can be indexed as (002) and (021) of monoclinic $\mathrm{ZrO}_{x}$.

Low-loss and high-loss EELS spectra collected from the area marked in Fig. 6(a) at different temperature during the in-situ heating from RT to $700{ }^{\circ} \mathrm{C}$ are shown in Figure 8(a)-(b). The intensity of all low-loss EELS spectra has been normalized to the energy loss peak at $42 \mathrm{eV}$, which is attributed to an excitation of the $\mathrm{Zr} 4 p$ level electrons [41]. In the present study, we will focus on the energy loss peak ranging from $15 \mathrm{eV}$ to $20 \mathrm{eV}$. Only one peak is observed at $19.3 \mathrm{eV}$ for those spectra collected from RT to $425^{\circ} \mathrm{C}$, indicating that the hydride platelet is the $\delta-\mathrm{ZrH}_{1.5-1.66}$ and is thermally stable below $425{ }^{\circ} \mathrm{C}$. The energy loss peak in the spectrum collected at $450{ }^{\circ} \mathrm{C}$ started to shift towards to $18.3 \mathrm{eV}$, which belongs to the metastable $\gamma$-ZrH phase $[14,16,23]$. With the temperature increasing to $475{ }^{\circ} \mathrm{C}$, the energy loss peak shifts to $17.3 \mathrm{eV}$ that is ascribed to the energy loss of $\mathrm{Zr}$ element in the chemical states of $\zeta-\mathrm{ZrH}_{0.25-0.5}[16]$. The EELS spectra remain the same during the following 
heating up to $700{ }^{\circ} \mathrm{C}$. In Fig. 8(b), no obvious energy loss peak of oxygen was found around $532 \mathrm{eV}$ in the EELS high-loss region spectra, indicating that $\mathrm{Zr}$ hydride is free of oxidation during the decomposition. The above in-situ EELS results demonstrate that the $\delta-\mathrm{ZrH}_{1.5-1.66}$ is thermally stable below $450{ }^{\circ} \mathrm{C}$, and afterwards, it would be decomposed to $\zeta-\mathrm{ZrH}_{0.25-0.5}$ which stably exists up to $700{ }^{\circ} \mathrm{C}$. The stability of the $\zeta$ - and $\delta$-type hydrides concluded from the EELS analysis is consistent with our in-situ SAED study.

As mentioned above, the $\mathrm{Zr}$ hydride phase transformation from $\delta-\mathrm{ZrH}_{1.5-1.66}$ to $\zeta-\mathrm{ZrH}_{0.25-0.5}$ was confirmed to occur at $450{ }^{\circ} \mathrm{C}$. The results on the transformation temperature and decomposition products are contrary to those found in the literatures $[7,10,13,19-21$, $23,26]$. The reason for the stability of the hydrides in the present work differing from those in the literatures might be due to the effect from the $\mathrm{Zr}$ matrix, such as stress state, defect structure and yield strength. Moreover, our results confirm that the $\zeta-\mathrm{ZrH}_{0.25-0.5}$ is stable up to $700{ }^{\circ} \mathrm{C}$ even though $\alpha$ - Zr has been recognized as the final decomposition product $[13,21]$. The existence of the $\zeta-\mathrm{ZrH}_{0.25-0.5}$ at $700{ }^{\circ} \mathrm{C}$ suggests that it has been stabilized by the dissolved $\mathrm{ZrO}_{x}$ matrix. The main reason might be attribute to the stress state of $\mathrm{Zr}$ crystalline matrix which could enhance hydrogen reordering and phase transformation from $\zeta-\mathrm{ZrH}_{0.25-0.5}$ to $\alpha-\mathrm{Zr}$ in a bulk sample.

\section{Conclusions}

In summary, we have reported the direct observation of the hydrogenation and dehydrogenation of the $\mathrm{Zr}$ hydride platelet in a $\mathrm{Zr}$ alloy. The reaction of the $\mathrm{Zr}$ alloy with $\mathrm{H}$ generated by the decomposition of the organometallic precursor induces the precipitation of $\mathrm{Zr}$ hydrides. The formed $\delta$-type $\mathrm{Zr}$ hydrides have a fcc structure and exist as preferentially oriented platelets with a common crystallographic relationship of $[010]_{\alpha} / /[1-10]_{\delta}$, $(001)_{\alpha} / /(111)_{\delta}$ with respect to the $\mathrm{Zr}$ matrix. The stress is confirmed as a crucial factor 
enhancing the formation of $\mathrm{Zr}$ hydride. The $\delta$-type hydride is thermally stable up to $450{ }^{\circ} \mathrm{C}$. Then, it desorbs $\mathrm{H}$ atoms and undergoes a phase transition to the $\zeta$-type hydride, which is stable up to $700{ }^{\circ} \mathrm{C}$ for this sample configuration (i.e. thin, FIB milled, flash polished). The presented methodology may also be applied to the studies of hydrogenation behaviors of other metallic alloys for $\mathrm{H}$ storage like palladium.

\section{Acknowledgment}

This research was funded by the Key Laboratory of Neutron Physics of China Academy of Engineering Physics (Grant No. 2012AB02), the Fundamental Research Funds for the Central Universities of Ministry of Education of China (Grant No. ZYGX2012YB017), and the Ph.D. Funding Support Program of Education Ministry of China (Grant No. 20110185110007). The JEOL-2010F TEM and the JEOL-2100F TEM used for this investigation were funded by National Science Foundation Grants (Grant No. DMR-9871177 and DMR-0723032) and the Helios FIB under the support of the College of Engineering at University of Michigan.

\section{References}

[1] R.S. Rochlin. Preparation of Tritium-Zirconium Targets, Rev. Sci. Instrum. 23 (1952) 100-101.

[2] G. Huang, X.G. Long, S.M. Peng, J.H. Liang, B.F. Yang. Studies on the Characteristic of Zirconium-Tritium Reaction, J. Fus. Energy 30 (2011) 7-12.

[3] L.Q. Shi, G.Q. Yan, J.Y. Zhou, S.Z. Luo, S.M. Peng, W. Ding, X.G. Long. Investigation of the hydrogenation properties of $\mathrm{Zr}$ films under unclean plasma conditions, J. Vac. Sci. Technol. A 20 (2002) 1840-1845.

[4] X.T. Zu, K. Sun, M. Atzmon, L.M. Wang, L.P. You, F.R. Wan, J.T. Busby, G.S. Was, R.B. Adamson. Effect of proton and Ne irradiation on the microstructure of Zircaloy 4, Philos. Mag. 85 (2005) 649-659. 
[5] H.H. Shen, S.M. Peng, X.S. Zhou, K. Sun, L.M. Wang, X.T. Zu. Microstructure evolution of zircaloy-4 during $\mathrm{Ne}$ ion irradiation and annealing: An in situ TEM investigation, Chin. Phys. B 23 (2014) 36102.

[6] X.T. Zu, L. Yang, F. Gao, S.M. Peng, H.L. Heinisch, X.G. Long, R.J. Kurtz. Properties of helium defects in bcc and fcc metals investigated with density functional theory, Phys. Rev. B 80 (2009) 054104.

[7] W.E. Wang, D.R. Olander. Thermodynamics of the Zr-H System, J. Am. Ceram. Soc. 78 (1995) 3323-3328.

[8] A. Grib, G. Khadzhay, B. Merisov, D. Vinogradov, M. Tikhonovsky. Kinetics of hydrogen in Zr-H and Zr-D systems, Int. J. Hydrogen Energy 35 (2010) 5442-5447.

[9] S. Yamanaka, D. Setoyama, H. Muta, M. Uno, M. Kuroda, K. Takeda, T. Matsuda. Characteristics of zirconium hydrogen solid solution, J. Alloys Compd. 372 (2004) 129-135.

[10]A. Steuwer, J.R. Santisteban, M. Preuss, M.J. Peel, T. Buslaps, M. Harada. Evidence of stress-induced hydrogen ordering in zirconium hydrides, Acta Mater. 57 (2009) 145-152.

[11]M. Grosse, M.v.d. Berg, C. Goulet, A. Kaestner. In-situ investigation of hydrogen diffusion in Zircaloy-4 by means of neutron radiography, J. Phys. Conf. Series 340 (2012) 012106.

[12]K.B. Colas, A.T. Motta, J.D. Almer, M.R. Daymond, M. Kerr, A.D. Banchik, P. Vizcaino, J.R. Santisteban. In situ study of hydride precipitation kinetics and re-orientation in Zircaloy using synchrotron radiation, Acta Mater. 58 (2010) $6575-6583$.

[13]C. Zhao, X. Song, Y. Yang, B. Zhang. Hydrogen absorption cracking of zirconium alloy in the application of nuclear industry, Int. J. Hydrogen Energy 38 (2013) 10903-10911.

[14]L. Lanzani, M. Ruch. Comments on the stability of zirconium hydride phases in Zircaloy, J. Nucl. Mater. 324 (2004) 165-176.

[15]J.K. Fink, L. Leibowitz. Thermal conductivity of zirconium, J. Nucl. Mater. 226 (1995) 44-50.

[16]Z. Zhao, J.P. Morniroli, A. Legris, A. Ambard, Y. Khin, L. Legras, M. Blat-Yrieix. Identification and characterization of a new zirconium hydride, J. Microsc. 232 (2008) 410-421.

[17]M. Kuroda, S. Yamanaka. Assessment of the Combined Effects of Irradiation and Hydrogenation on the Fracture Behavior of Zircaloy Fuel Claddings by Fracture 
Mechanics, J. Nucl. Sci. Technol. 39 (2002) 234-240.

[18]Y. Shinohara, H. Abe, T. Iwai, N. Sekimura, T. Kido, H. Yamamoto, T. Taguchi. In Situ TEM Observation of Growth Process of Zirconium Hydride in Zircaloy-4 during Hydrogen Ion Implantation, J. Nucl. Sci. Technol. 46 (2009) 564-571.

[19]K.G. Barraclough, C.J. Beevers. Some observations on the phase transformations in zirconium hydrides, J. Nucl. Mater. 34 (1970) 125-134.

[20]X. Hu, K.A. Terrani, B.D. Wirth. Hydrogen desorption kinetics from zirconium hydride and zirconium metal in vacuum, J. Nucl. Mater. 448 (2014) 87-95.

[21]M. Ma, L. Liang, B. Tang, W. Xiang, Y. Wang, Y. Cheng, X. Tan. Decomposition kinetics study of zirconium hydride by interrupted thermal desorption spectroscopy, J. Alloys Compd. In press.

[22]P. Vizcaíno, A.D. Banchik, J.P. Abriata. Solubility of hydrogen in Zircaloy-4: irradiation induced increase and thermal recovery, J. Nucl. Mater. 304 (2002) 96-106.

[23]E. Tulk, M. Kerr, M.R. Daymond. Study on the effects of matrix yield strength on hydride phase stability in Zircaloy-2 and Zr-2.5wt\%Nb, J. Nucl. Mater. 425 (2012) 93-104.

[24]K.A. Terrani, M. Balooch, D. Wongsawaeng, S. Jaiyen, D.R. Olander. The kinetics of hydrogen desorption from and adsorption on zirconium hydride, J. Nucl. Mater. 397 (2010) 61-68.

[25] S.C. Lumley, R.W. Grimes, S.T. Murphy, P.A. Burr, A. Chroneos, P.R. Chard-Tuckey, M.R. Wenman. The thermodynamics of hydride precipitation: The importance of entropy, enthalpy and disorder, Acta Mater. 79 (2014) 351-362.

[26] T.B. Flanagan, N.B. Mason, H.K. Birnbaum. The effect of stress on hydride precipitation, Scripta Metall. 15 (1981) 109-112.

[27]D. Khatamian. Effect of $\beta-\mathrm{Zr}$ decomposition on the solubility limits for $\mathrm{H}$ in $\mathrm{Zr}-2.5 \mathrm{Nb}, \mathrm{J}$. Alloys Compd. 356-357 (2003) 22-26.

[28]A. Baldi, T.C. Narayan, A.L. Koh, J.A. Dionne. In situ detection of hydrogen-induced phase transitions in individual palladium nanocrystals, Nat. Mater. 13 (2014) 1143-1148.

[29]H.H. Shen, S.M. Peng, X. Xiang, F.N. Naab, K. Sun, X.T. Zu. Proton irradiation effects on the precipitate in a $\mathrm{Zr}-1.6 \mathrm{Sn}-0.6 \mathrm{Nb}-0.2 \mathrm{Fe}-0.1 \mathrm{Cr}$ alloy, J. Nucl. Mater. 452 (2014) 335-342.

[30]H.H. Shen, J.M. Zhang, S.M. Peng, X. Xiang, K. Sun, X.T. Zu. In situ TEM investigation of amorphization and recrystallization of $\mathrm{Zr}(\mathrm{Fe}, \mathrm{Cr}, \mathrm{Nb})_{2}$ precipitates under 
Ne ion irradiation, Vacuum 110 (2014) 24-29.

[31]J. Mayer, L.A. Giannuzzi, T. Kamino, J. Michael. TEM Sample Preparation and FIB-Induced Damage, MRS Bull. 32 (2007) 400-407.

[32]K. Fujii, K. Fukuya. Characterization of defect clusters in ion-irradiated A533B steel, J. Nucl. Mater. 336 (2005) 323-330.

[33] V. Perovic, G.C. Weatherly, C.J. Simpson. Hydride precipitation in $\alpha / \beta$ zirconium alloys, Acta Metall. 31 (1983) 1381-1391.

[34]K. Une, K. Nogita, S. Ishimoto, K. Ogata. Crystallography of Zirconium Hydrides in Recrystallized Zircaloy-2 Fuel Cladding by Electron Backscatter Diffraction, J. Nucl. Sci. Technol. 41 (2004) 731-740.

[35]A.T.W. Barrow, A. Korinek, M.R. Daymond. Evaluating zirconium-zirconium hydride interfacial strains by nano-beam electron diffraction, J. Nucl. Mater. 432 (2013) 366-370.

[36]O.T. Woo, G.J.C. Carpenter. EELS characterization of zirconium hydrides, Microsc. Microanal. Microstruct. 3 (1992) 35-44.

[37]D.G. Carr, M.I. Ripley, D.W. Brown, S.C. Vogel, T.M. Holden. Residual stress measurements on a stress relieved Zircaloy-4 weld by neutron diffraction, J. Nucl. Mater. 359 (2006) 202-207.

[38]J.H. Root, M. Hayashi, C.E. Coleman, J.W. Bowden. Residual Stresses in Steel and Zirconium Weldments, J. Press. Vess. Technol. 119 (1997) 137-141.

[39]W.F. van Dorp, C.W. Hagen. A critical literature review of focused electron beam induced deposition, J. Appl. Phys. 104 (2008) 081301.

[40]J.D. Wnuk, J.M. Gorham, S.G. Rosenberg, W.F. van Dorp, T.E. Madey, C.W. Hagen, D.H. Fairbrother. Electron Induced Surface Reactions of the Organometallic Precursor Trimethyl(methylcyclopentadienyl)platinum(IV), The J. Phys. Chem. C 113 (2009) 2487-2496.

[41]C. Palacio, J.M. Sanz, J.M. Martinez-Duart. Low energy electron emission and EELS of clean and oxidised zirconium, Surf. Sci. 191 (1987) 385-394. 


\section{Figure Captions}

Fig. 1. A series of SEM images captured during the final milling of the lamella prepared by FIB technique. From (a) to (f), the thickness of thin lamella decreases to a finally thickness of nearly $100 \mathrm{~nm}$. The thin lamella was ion milling by two steps: ion milling on the right side $((\mathrm{a}) \sim(\mathrm{c}))$ and then on the left side $((\mathrm{d}) \sim(\mathrm{f}))$ of the lamella. Many platelets denoted by arrows appear in the area where the ion beam was targeting on.

Fig. 2. STEM-BF images taken from the same area of the $\mathrm{Zr}$ alloy with a grain boundary shown in the center (a) before and (b) after the final ion milling procedure.

Fig. 3. (a) HRTEM images and (b) SAED patterns taken from the $\alpha$-Zr matrix and the $\delta$-type Zr hydride. The magnified HRTEM images for Zr matrix and Zr hydride captured from the denoted areas in (a) were shown in (c) and (d), respectively.

Fig. 4. (Color online) (a) BF image of one Zr hydride platelet with positions A and B marked from which EEL spectra were taken. (b) EELS spectra collected from A and B corresponding to the areas of the $\mathrm{Zr}$ matrix and the $\mathrm{Zr}$ hydride platelet, respectively. The labeled peaks 1 and 2 in (b) reveal the chemical state of the element of $\mathrm{Zr}$ in pure Zr and the $\delta$-type Zr hydride. (c) The EELS line scan collected along the line labeled in (a) is plotted from top to bottom. The specific EELS spectra of the Zr matrix and the $\delta$-type Zr hydride are shown at the bottom. Two points marked by arrows in the line profile indicate the region that has not been hydrogenated. (d) Element map collected using EELS from the rectangle area denoted in (a) are colored by red and green corresponding to the energy loss peaks of $16.9 \mathrm{eV}$ and $19.2 \mathrm{eV}$ in the EELS spectra representing the $\mathrm{Zr}$ matrix and the $\delta$-hydride.

Fig. 5. (a) and (c) side views and (b) and (d) top views of the final thin lamella prepared by two kinds of final ion milling procedures: $((a) \sim(b))$ conventional ion milling; ((c) 
(d)) gradient ion milling: only the selected area indicated by the rectangle frame is final milled down to around $100 \mathrm{~nm}$.

Fig. 6. BF images ((a) - (c)) and SAED patterns ((d) - (f)) from one Zr hydride platelet taken at temperatures of RT, $450{ }^{\circ} \mathrm{C}$ and $700{ }^{\circ} \mathrm{C}$. The SAED pattern in (d) is indexed as the $\delta$-type Zr hydride along its [110] zone axis. The SAED patterns in (e) and (f) are indexed as the $\zeta$-type $\mathrm{Zr}$ hydride along its [12-1] zone axis. The polycrystalline rings shown in all the SAED patterns ((d) - (f)) are ascribed to Zr oxides in the dissolved matrix.

Fig. 7. SAED patterns taken from the hydride platelet that has been heated to $700{ }^{\circ} \mathrm{C}$ along three different zone axes via tilting the platelet which are indexed as [12-1], [-13-1] and [35-1] zone axes of the $\zeta$-type $\mathrm{Zr}$ hydride shown in (a), (b) and (c), respectively.

Fig. 8. (Color online) The low-loss (a) and high-loss (b) regions of EELS spectra collected from the denoted area in Fig. 6(a) at different temperatures during the in-situ heating from RT to $700{ }^{\circ} \mathrm{C}$. Three energy loss peaks of $17.3 \mathrm{eV}, 18.3 \mathrm{eV}$ and $19.3 \mathrm{eV}$, corresponding to the $\zeta$-hydride, $\gamma$-hydride and $\delta$-hydride, are labeled in (a) with dash lines. The dash line labeled in (b) reveals the energy loss peak of oxygen element. 
Figure 1.
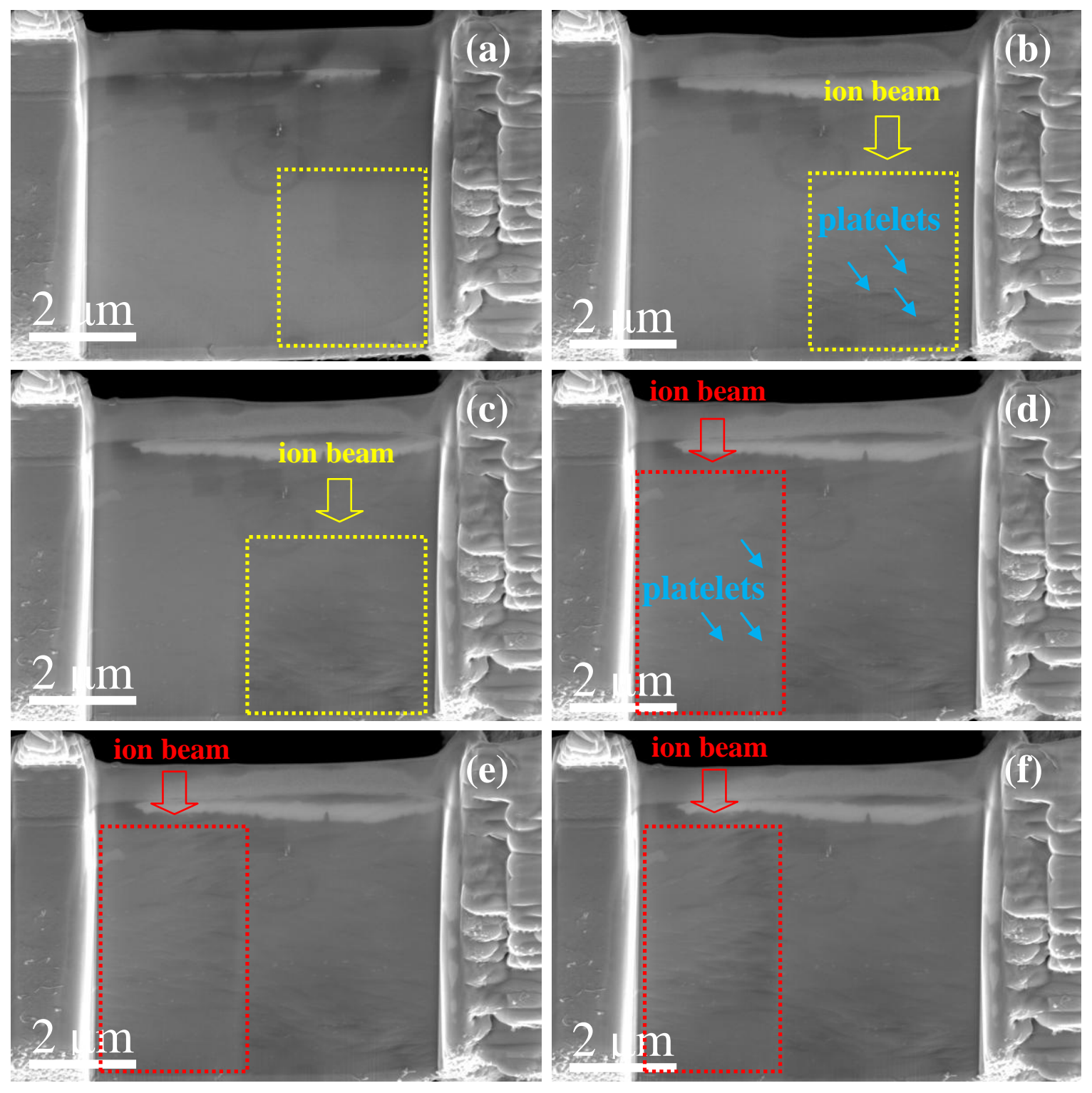

$2 \mathrm{~m}$
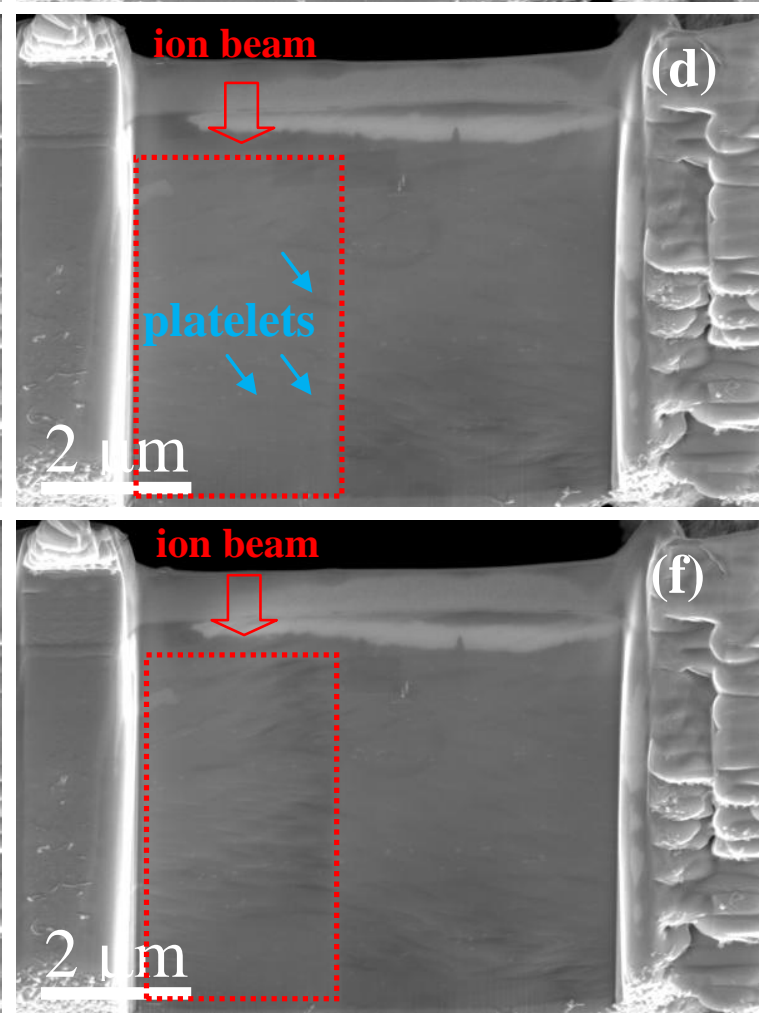
Figure 2.
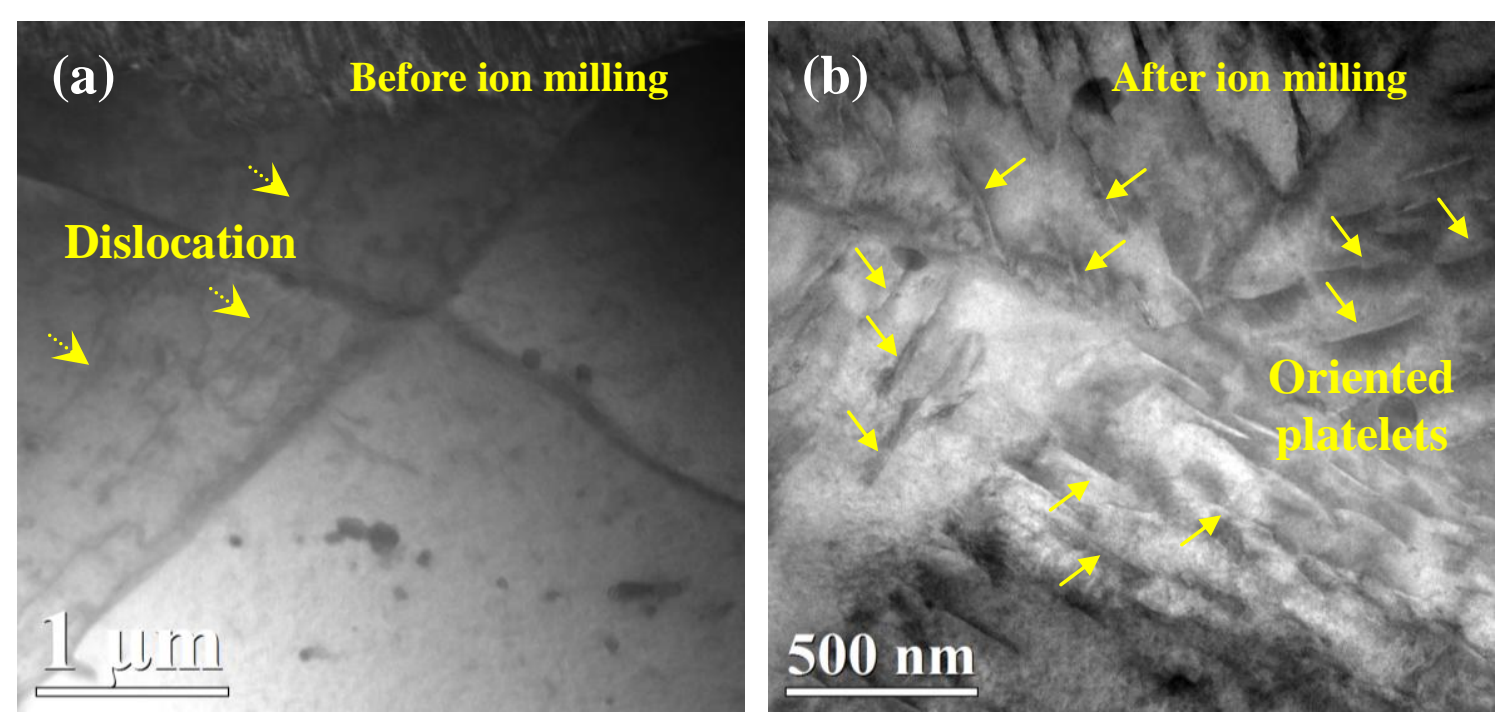
Figure 3.
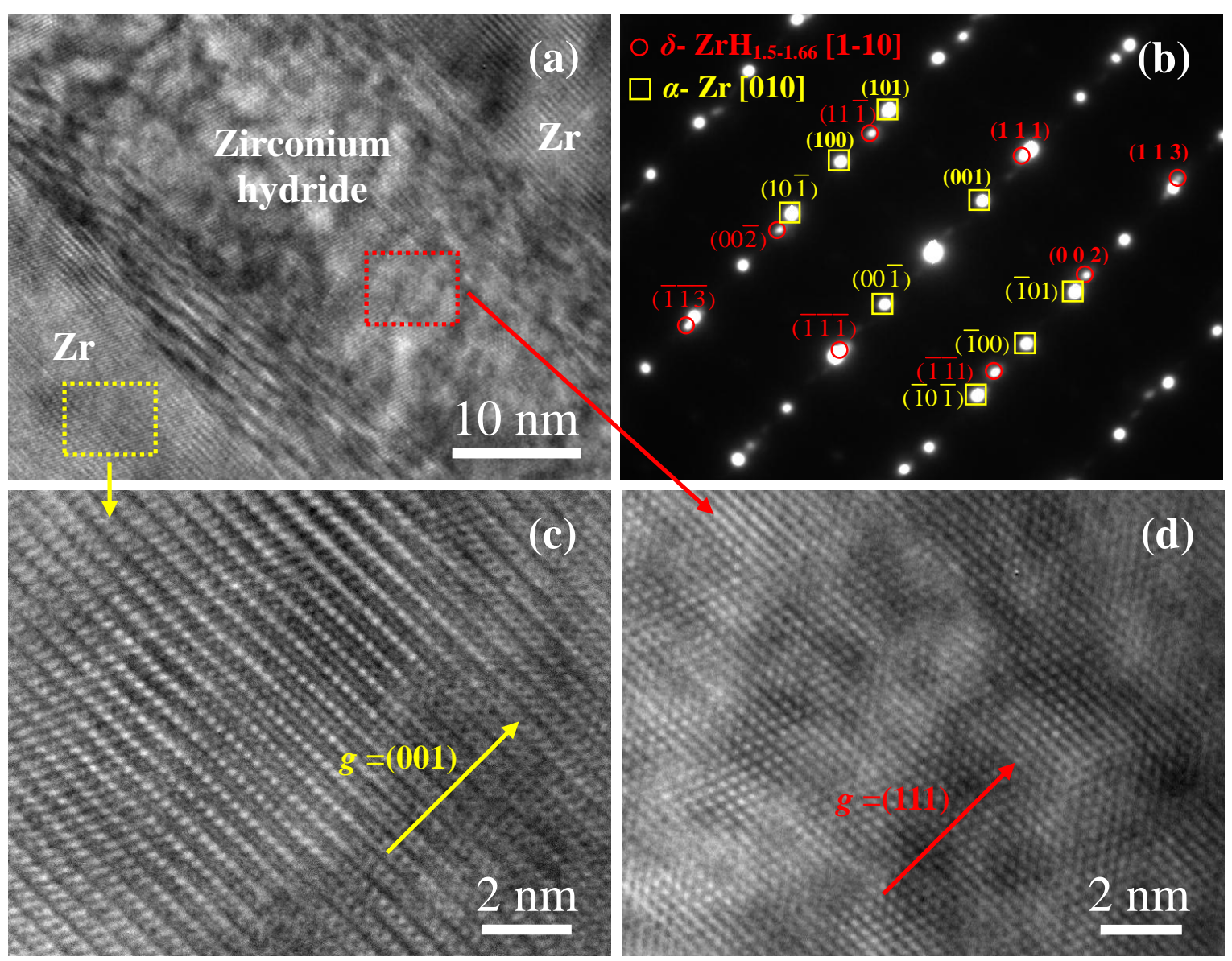
Figure 4.
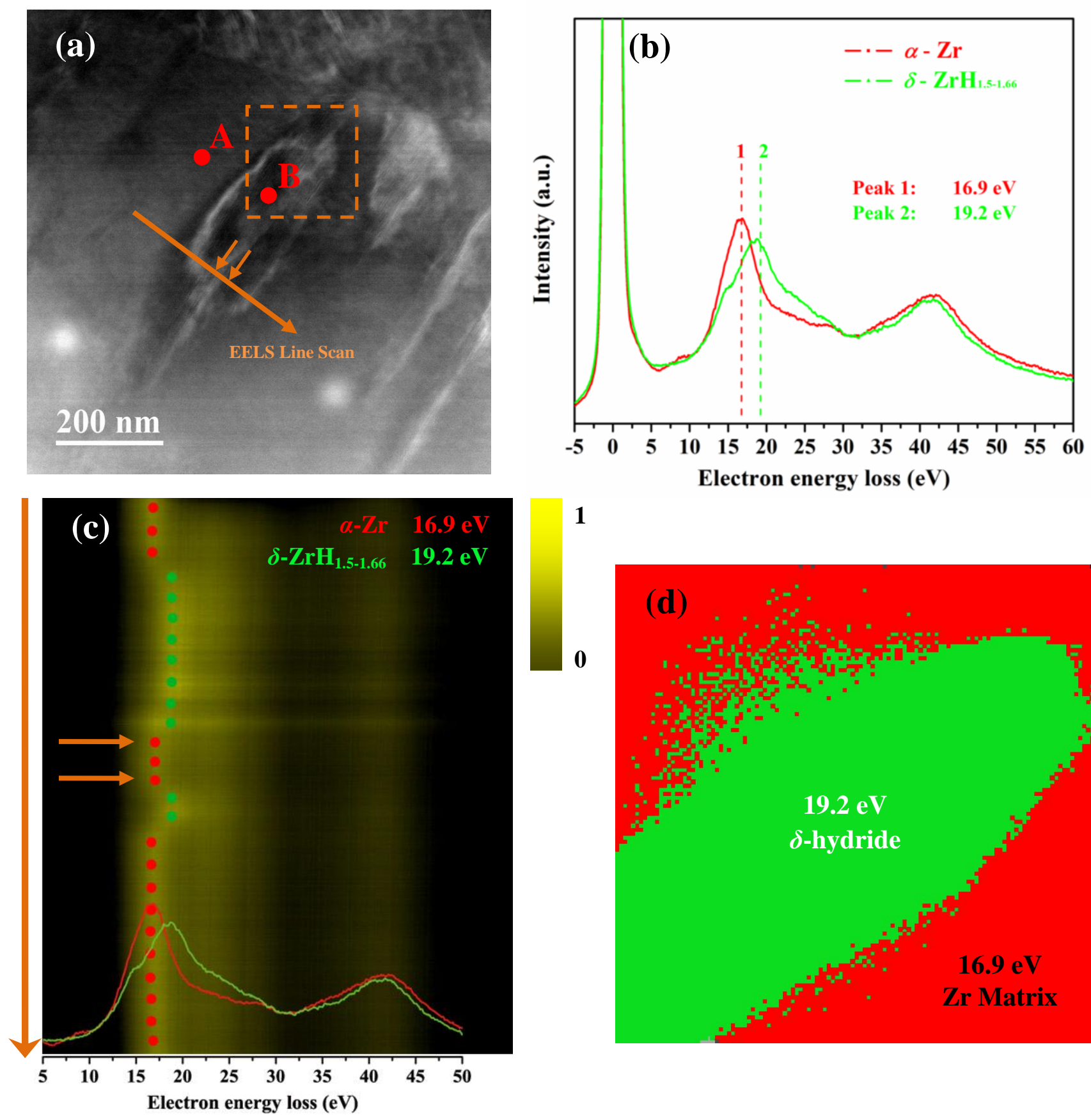
Figure 5.

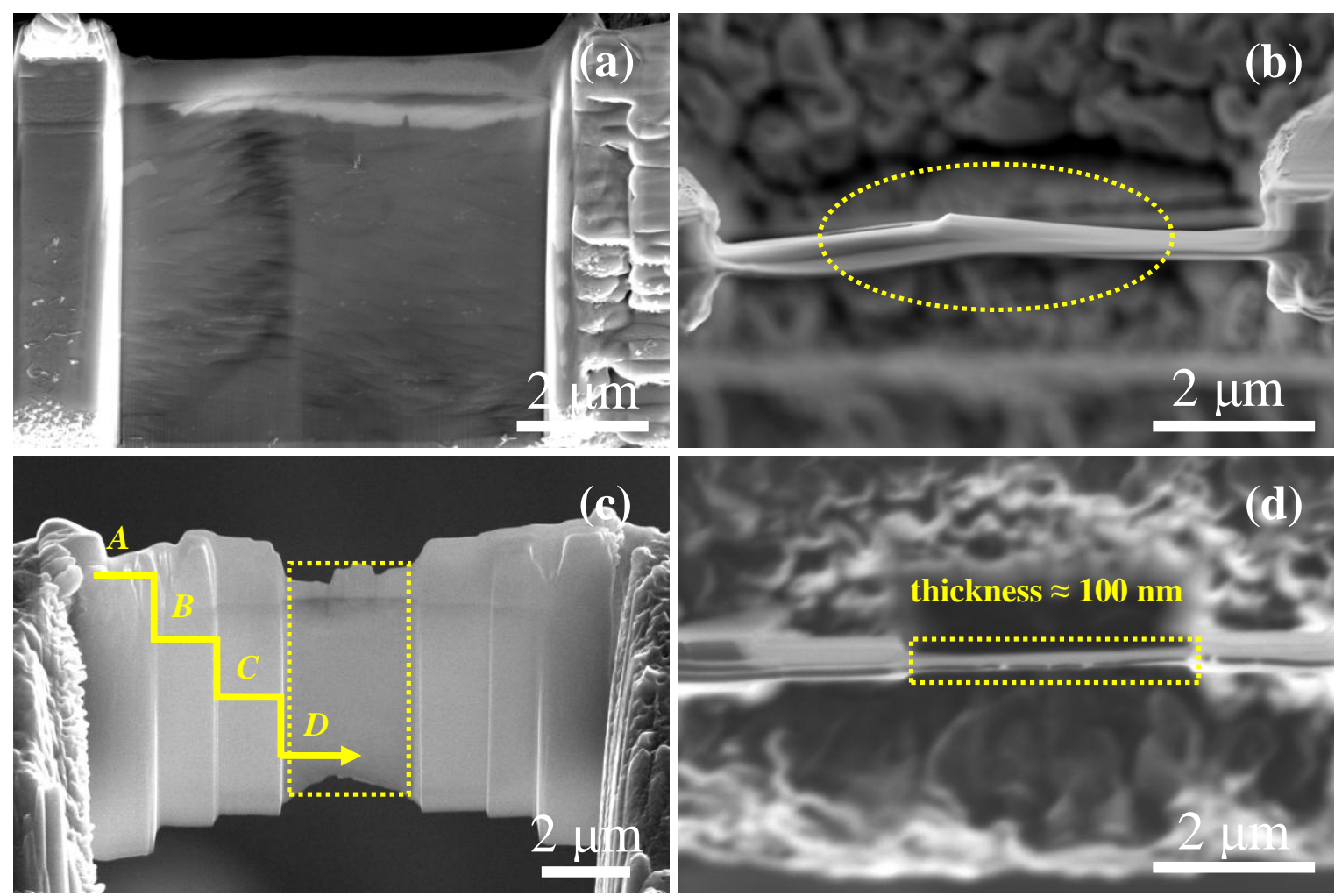


Figure 6.
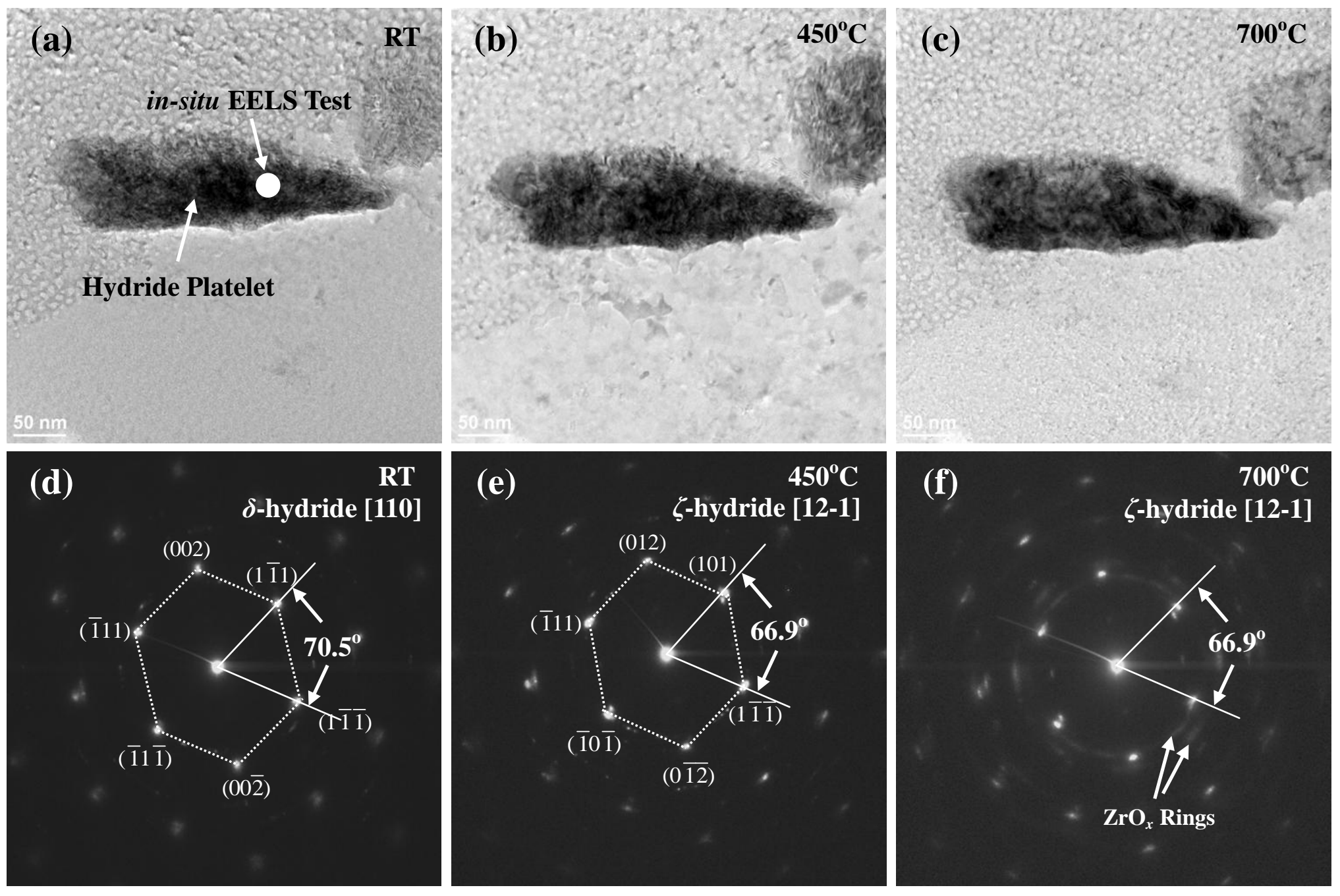
Figure 7.

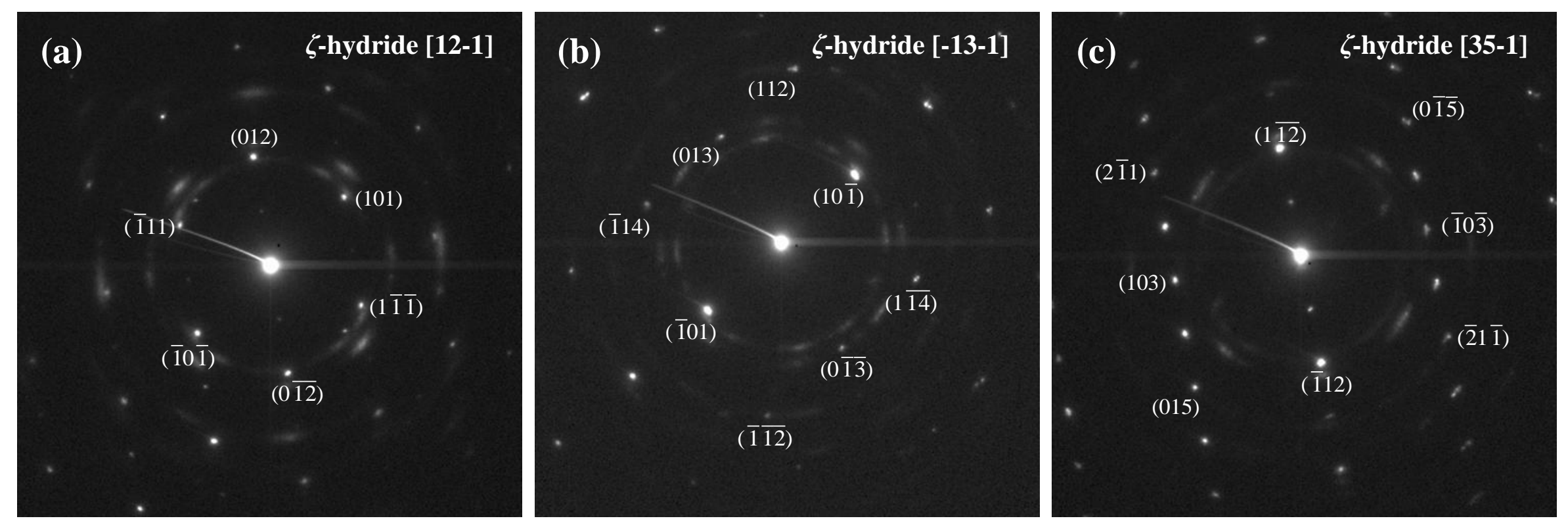


Figure 8.
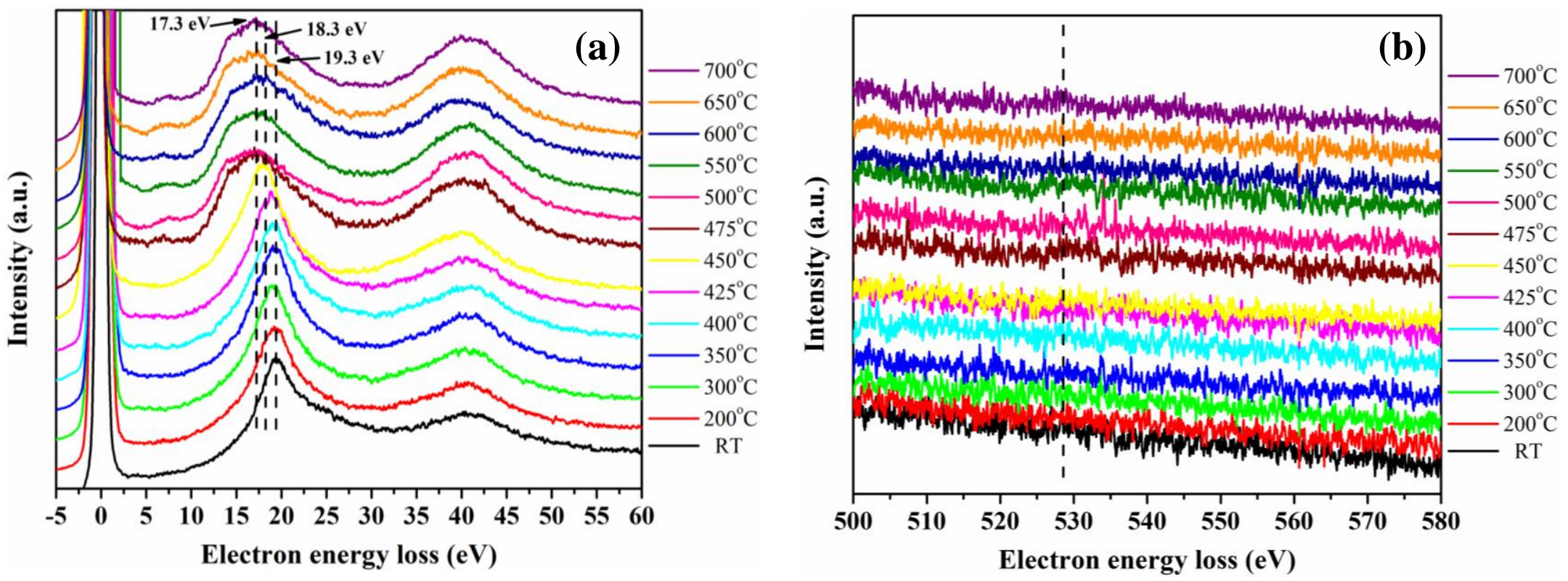